\title{
〔第49回総会シンポジウム ディジタルX線画像の最適化一被曝線量の観点から一〕
}

\section{2. ディジタルシステムにおける撮影条件}

東 田善 治

熊本大学医療技術短期大学部

Key words: Radiographic condition, Digital system, Computed radiography, Detectability

\section{RADIOGRAPHIC CONDITION IN A DIGITAL SYSTEM}

\author{
YOSHIHARU HigASHIDA
}

Kumamoto University, College of Medical Science

\section{Summary}

This paper deals with the optimum radiographic condition in digital radiographic systems. Radiographic conditions for chest and bone radiography with the computed radiographic (CR) system were reviewed. The effect of incident exposure on the detectability of various abnormalities including nodule, pneumothorax, asbestosis, fine pulmonary line and other abnormalities were also discussed.

Radiographic conditions for radiography with portable X-ray unit and CR system were investigated at several institutions. Chest and abdominal examinations with the $\mathrm{CR}$ system were performed under the same exposure conditions as those of screen-film systems. However, large fluctuations in the radiographic condition were found by some technologists.

\section{1.はじめに}

X線撮影における撮影条件を, 従来のアナログ系（増 感紙-フィルム系) とディジタル系で比較すると, 堌感紙 一フィルム系では，使用する系によって撮影条件（線量） がほほ決められ，その結果，患者被曝線量も決定される。 これに対して, I.I.-TV 系あるいは輝尽性蛍光体 (imaging plate：IP) を用いたディジタル系では, 光学系や高 電子増倍管の感度とラチチュードを変化させることによ って, 入射線量の多少にかかわらず常に一定の写真濃度 を得ることが可能である。このことは同一部位のX線写 真を撮影するときの患者被曝線量が, 術者（主として放 射線技師）あるいは施設によって異なる可能性が考えら れる。

現在ディジタルシステムに使用されている撮影条件は, 各施設で使用されている増感紙一フィルム系の条件を一
つの指標にして決定されている場合が多い. しかし今後 ディジタル化が一層進むと,施設によっては増感紙-フィ ルム系を全く使用しない状況がでることも予想され，こ れまで永年にわたって築いてきた，X線撮影における[条 件論]が崩れていくことも考えられる。

本シンポジウムの目的は，撮影条件または患者被曝線 量の観点からディジタルシステム，あるいはディジタル 画像の最適化を検討することである。ここではこれまで 報告された論文の中から主として CR (computed radiography）の論文を中心に，画質あるいは病変の検出能と 被懪線量という観点から文献的考察を行う。またいくつ かの部位における撮影線量を調查し, 患者被曝線量の違 いについても検討を加える。

\section{CR システムにおける撮影条件}

$2.1 \mathrm{CR}$ システムの基本的な考え方 
CR システムは，現在臨床で使用されているディジタ ル装置の中で最も優れた物理特性を有しており，増感紙 ーフィルムに置き代るシステムとして位置づけられてい

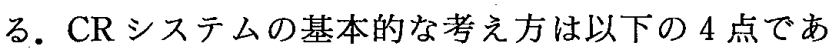
$る^{1) \sim 3)}$.

1）被曝線量の低減

2）広いラチチュードを持ち,診断情報が豊富であるこ と

3）画像処理による新しい䛦断法の展開

4）画像情報のディジタル化による保管,検索などへの 対応

上記のいくつかについては，当初期待された効果が得 られていないものもある. 被曝線量低減の可能性につい ても, CR システム導入時は大きな期待が持たれたが, 現 在では特殊な撮影部位を除いてほほ増感紙ーフィルムと 同等線量で撮影されている可能性が強い.

\section{2 被曝線量低減の考え方}

$\mathrm{X}$ 線撮影時の患者被曝線量低減には, 次の 2 つのアプ ローチが考えられる。

1）再撮影の減少による被儤線量の低減

$\mathrm{CR}$ システムは, 読みとり部の感度, 画像レンジ自動設 定機構により，撮影線量の大小にかかわらず常に適正な 濃度の写真を得ることが出来る。この特性は病変の状態 を経時的に観察する場合や，ポータブル撮影において特 に有効である. Table 1 にポータブル撮影に括ける CR と増感紙ーフィルムシステムの再撮影率を示す4). 1 日平 均130名のポータブル撮影を行っているが（このうち約 110名が胸部撮影), CR による再撮影率は約 $1 \%$ で, 増感
紙ーフィルム法の $4.5 \% に$ に比べ著しく少ない. また他の報 告では，通常システムの $6 \%$ に比べ CR システムでは 1 \%の再撮影率となっている. CR システムをポータブル 撮影に用いることにより再撮影率が大きく減少し，患者 被懪線量に大きく笴与することを示している，CRによ る再撮影率はいずれも撮影時の患者の整位に問題があっ たと報告されている。

2） 1 回撮影における撮影線量の低減

$\mathrm{CR}$ による撮影線量は, CR 画像の物理特性や病変の検 出能と深く関係しているため簡単には決定できない. こ のため CR システムにおける撮影条件は，一般的には各 施設で使用されている増感紙ーフイルム系の条件を指標 にしたり，CR システムの S 值を参考にしていると考え られる。

CR システムを用いた被曝線量低減を有効に行うため には，撮影目的を明確にすることがまず必要であろう。

Fig. 1 に示すように，撮影目的が比較的限定されている いくつかの部位では大幅な線量低減が可能であり，いく つかの報告が見られる5)。 しかし CR システムの設計思 想は,増感紙一フルム系に代わるものとして考えられて いるため，むしろ他の部位に庍用されることが多い。

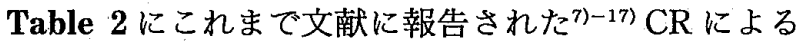
胸部検查の撮影条件を示す. CR の撮影条件は各施設で 用いられている堌感紙ーフィルム系を基準に決定されて おり,全ての増感紙一フィムム系と同等線量で撮影されて いる. Table 3 に同等線量で撮影されたときのいろいる な疾患の検出能の比較を示す。報告者や病変の種類によ って，CR と堌感紙-フィルム系の検出能に差が見られる

Table 1 Comparisom of the failure rate of radiography with a portable X-ray unit.

Radiographic system

Screen/film

C R

Screen/film

C R

\section{Repeat rate}

\section{$4.5 \% *$ \\ $<1 \% *$ \\ (positioning error)}

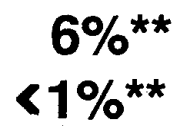

${ }^{\star} 130$ portable studies/day (110 are chest examinations)

Sagel et al. (J Thorac Imag, 1990)

${ }^{\star \star}$ Murphey et al. (AJR, 1992) 
1. Scoliosis

(Cobb angle measurement, apical vertebrae)

2. Children (Legg-Perthes disease, congenital hip dysplasia )

\section{Pelvimetry}

\section{ICU(intensive care unit)} (catheter, tube)

\section{Pediatric chest}

Fig. 1 Region where a reduction in patient exposure is expected.

Table 2 Comparison of the radiographic condition with screen-film and CR systems for chest radiography.

\begin{tabular}{|lccl|}
\hline Authors & $\begin{array}{c}\text { Tube Potentials } \\
(\mathbf{k V})\end{array}$ & Screen/Film & CR \\
\hline Newell et al & 124 & Medium Speed & Iso dose \\
Onitsuka & 120 & BM-III/RX & Iso dose \\
Oestmann et al & 141 & Lanex Medium/OC & Iso dose \\
Oestmann et al & 141 & Lanex Medium/OC & Iso dose \\
Fajardo et al & 105 & Quanta-III/SR334 & Iso dose \\
Schaefer et al & 141 & Lanex Medium/OC & Iso dose \\
Schaefer et al & 141 & Lanex Medium/OC & Iso dose \\
Higashida & 140 & BH-II/RX & Iso dose \\
Schaefer et al & 140 & Lanex Medium/OC & Iso dose \\
Akita & 140 & HR4/HRS & Iso dose \\
Carr et al & 120 & Quanta-III/Cronex & Iso dose \\
& & & \\
\hline
\end{tabular}

Table 3 Comparison of the detectability for chest diseases with screen-film and CR systems.

\begin{tabular}{|c|c|c|}
\hline Authors & Subjects & Detectability \\
\hline $\begin{array}{l}\text { Newell et al } \\
\text { Onituka } \\
\text { Oestmann et al } \\
\text { Fajardo et al } \\
\text { Schaefer et al } \\
\text { Schaefer et al }\end{array}$ & $\begin{array}{l}\text { *nodule } \\
\text { *nodular,interstitial, } \\
\text { *alveolar pattern } \\
\text { *fine pulmonary line } \\
\text { pneumothorax } \\
\text { asbestosis } \\
\text { chest diseases } \\
\text { (overall) } \\
\text { (mediastinal ) } \\
\text { nodule } \\
\text { mediastinal abnormalities } \\
\text { interstitial lung diseases } \\
\text { pneumothorax }\end{array}$ & $\begin{array}{l}\text { comparable } \\
\text { comparable } \\
\text { CR inferior } \\
\text { CR superior } \\
\text { CR slightly inferior } \\
\text { CR superior } \\
\text { comparable } \\
\text { CR superior } \\
\text { comparable } \\
\text { CR superior } \\
\text { comparable } \\
\text { comparable }\end{array}$ \\
\hline
\end{tabular}

* simulated disease 
Table 4 Comparison of the detectability for bone diseases with screen-film and CR systems.

\begin{tabular}{|lll|}
\hline Authors & Subjects & Detectability \\
\hline Wilson et al & extremities & CR slightly inferior \\
Prokop et al & cortical bone defects & comparable \\
\hline
\end{tabular}

(Iso dose)

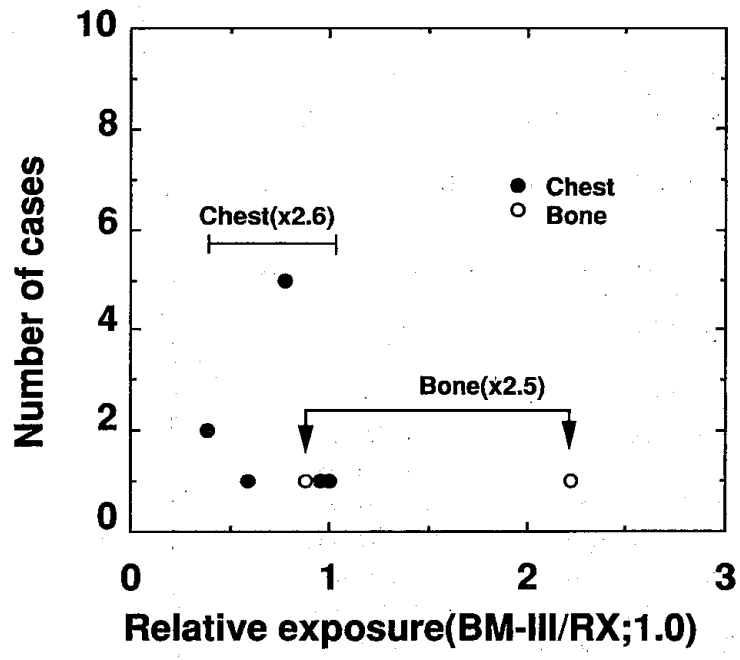

Fig. 2 Relative exposure for chest and bone radiograph with the $\mathrm{CR}$ system.

ケースもあるが，これには他の物理特性も大きく関係し ている.

Table 4 に同等線量で撮影したときの骨疾患の検出能 の比較を示す ${ }^{18) 19)}$. これら 2 つの部位における撮影線量 と報告例を Fig. 2 にまとめた。縦軸は報告の数を示し， 横軸は中等度感度の増感紙-フィルム系(BM-III/RX)を 1.0 として計算した相対線量を示す.施設によって線質が 異なっているので, 横軸の相対線量は䛊差が大きいと考 えられるが，胸部，骨撮影とも約2.5倍の線量差がある. この差は CR システムの撮影条件を考慮して決定された ものではなく,各施設で使用されている増感紙ーフィルム 系の違いによるものである。

\section{CR 撮影における撮影条件の調査}

CR システムを用いた胸部および腹部ポータブル撮影 の標準体厚の撮影条件をアンケートにより調查した. 12 施設に調查表を送ったが，このうち CR を胸部および腹 部ポータブルに使用している 6 施設から解答を得た. 6
施設では胸部, 腹部に中等度感度の増感紙ーフィルム系を 用いており，CR の撮影条件は全ての増感紙一フィム系 と同一条件で撮影していた．Fig. 3 に各施設で使用して いる増感紙一フィルム系と相対感度を示す。増感紙ーフィ ルム系の感度差は約25\%であり，6施設における胸部， 腹部の撮影線量の違いは一見少ないように見える。

Fig. 3 に示した施設の中で，1施設を選んで実際にポ ータブル撮影を行っている術者（放射線技師）の胸部と 腹部の撮影条件（電圧，電流，撮影時間）について聞き 取り調査を行った。Fig. 4 に胸部の結果を示す. $5 \mathrm{mAs}$ を用いている者が全体の75\%を占めるが，撮影者により 最大 2 倍の $\mathrm{mAs}$ の違いが見られる. 腹部ポータブル撮 影に怙ける撮影条件の違いを Fig. 5 に示すが, 術者によ って約 5 倍の $\mathrm{mAs}$ の違いが見られる. 術者による撮影 電王の違い（6 kV 程度）があるため， mAS の違いがそ のまま被儤線量には反映しないが, 増感紙一フィルム系と 同等線量で撮影していると答えた施設の中でも，術者に よって撮影条件が異なることを示している。

\section{4. 考察}

今回の報告では, $\mathrm{CR}$ システムの撮影条件について，ま ずこれまで報告されたいくつかの論文について調査した。 撮影対象は胸部，骨部および腹部としたが，これらの部 位には CR の撮影条件は各施設で使用されている増感紙 ーフィルム系と同じ条件（同等線量）が用いられており， この条件下での病変の検出能の比較が試みられている. 研究的には低線量撮影による報告も見られるが20), 一般 的には CRの撮影条件は増感紙-フィルム系と同等線量 が用いられていると見なすことができる.

アンケート調查でも，ポータブル撮影における胸部お よび腹部の CR の撮影条件は, 増感紙一フィルム系と同等 線量で撮影されている施設が多かった。しかし同等条件 


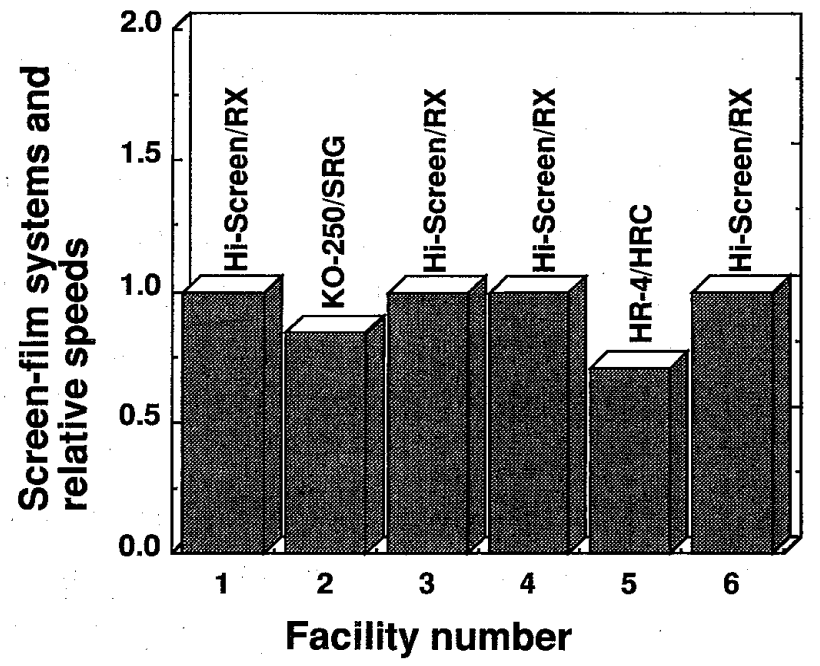

Fig. 3 Screen-film systems and their relative speeds used for chest and abdominal examinations.



Fig. 4 Fluctuation of the radiographic conditions for chest radiography with the $\mathrm{CR}$ system.

で撮影を行っていると答えた施設の中でも，撮影者によ って条件が異なるケースが見られた。胸部では撮影条件 の差は少なかったが, 腹部では撮影者によって 5 倍程度 の条件の差が見られた。撮影条件を増して撮影を行って いる根拠を 2,3 の術者に尋ねたが, 線量を増加させて X線量子ノイズの影響を少なくしょうという配慮をして いることがわかった。CR システムによる正確な撮影線 量の測定については現在調べており，今後報告する計画 である。

前述したように，今後放射線診断領域の中で CR の利 用が大きくなると従来の增感紙一フィルム系が用いられ ない施設も考元られる. CR の導入初期には増感紙一フ ルム系を指標にして決定した撮影条件が，次第に崩れて

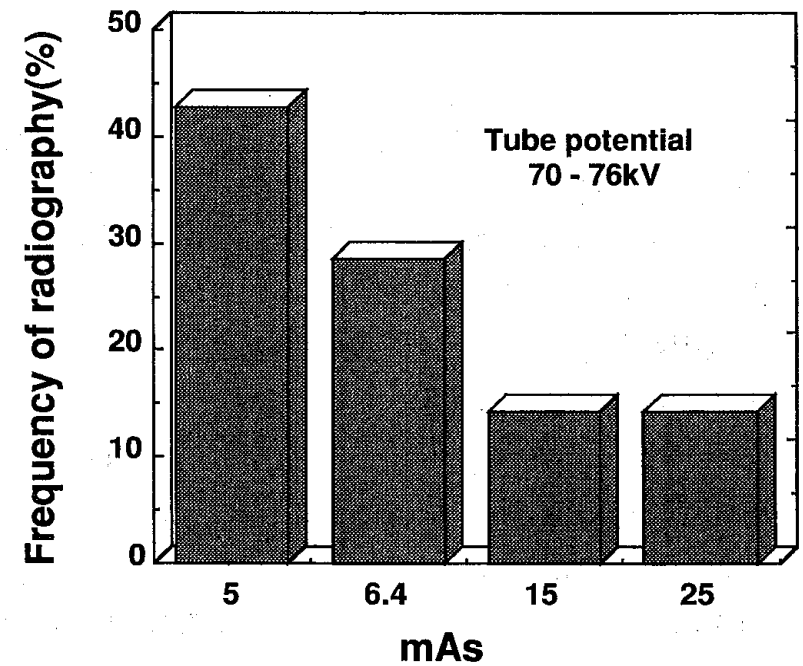

Fig. 5 Fluctuation of the radiographic conditions for abdominal radiography with the CR system

\section{Dose control \\ 1. Radiographic purpose \\ 2. Objective thickness \\ 3. Phototimer}

\section{Image quality control \\ 1. Quality of radiation (tube voltage) \\ 2. Dose \\ 3. Scatter \\ 4. System or detector response}

Fig. 6 Important factors for the optimum radiogrphic condition with the $\mathrm{CR}$ system.

行くことも予想できる. 画像処理を含めた最適撮影条件 の決定は, CR 画像をつくる立場にある放射線技師の重 要なテーマであり, CR システムが持っている多くの優 れた特性を臨床に生かすためにも今後取り組まなければ ならない問題である.また今後 $\mathrm{CR}$ システムの導入は, 放 射線技師に関して専門の知識を持っていない施設にも広 がることが予想される。これらの施設で CR システムが 適正に使われるためには, 現在のS 值のほかに撮影にあ たって線量をチェックできるような機構を取り入れるこ とも必要と考光られる。これらをまとめると,今後 $\mathrm{CR} シ$ ステムが臨床の場で適正に使われるためには, Fig. 6 に 示すように，画質管理と線量管理の両面から検討するこ とが必要であろう。

わが国におけるCR のシステムの実用画像処理に関し ては最近大規模な調査が行なわれたが211, 撮影線量の正 確な調查に関しても今後取り組まなければならない問題 である。 


\section{参考文献}

1）高野正雄：FCR の目的と背景. 日放技学会誌。 41 , 43-48, (1985).

2）山口 宏, 松永 剛, 服部憲二, 他：FCR の現状と 問題点. 日放技学会誌. 41，49-54，(1985).

3）診療画像学 I ーデイジタル画像の基礎と臨床一，日 本放射線技師会，(1989）。

4) Sagel SS, Jost RG, Glazer HS et al: Digital mobil radiography. Journal of thoracic imaging, 5, 36-48, (1990).

5）植松貞夫, 岡田淳一, 木川隆司, 他：脊柱側わん症 に対する集検システムの開発。映像情報，18，277280, (1986).

6）井村慎一, 中瀬裕介, 大橋義一, 他：低線量新生児 股間節検診ならびに乳児股間節 $\mathrm{X}$ 線撮影における FCR の有用性. 臨整外， 21，683-688，(1986).

7) Newell JD, Seeley G, Hagaman RM, et al: Computed radiographic evaluation of simulated pulmonary nodules; preliminary results. Invest Radiol. 23, 267-270, (1988).

8）鬼塚英雄：輝尽性蛍光体イメージング. プレートを 用いた胸部デジタルラジオグラフィーの診断能. 日 医放会誌，49，177-190，(1989).

9) Fajardo LL, Hillmam BJ, Pond GD, et al: Detection of pneumothorax: comparison of digital and conventional chest imaging. AJR. 152, 475480, (1989).

10) Oestmann JW, Green R, Rubens JR, et al : High frequency edge enhancement in the detection of fine pulmonary lines. Parity between storage phosphor digital image and conventional chest radiography. Invest Radiol. 24, 643-646, (1989).

11) Oestmann JW. Rubens JR, Bourgouin PM, et al : Impact of postprocessing on the detection of simulated pulmonary nodules with digital radiography. Invest Radiol. 24, 467-471, (1989).

12) Schaefer CM, Green R, Oliver LC, et al : Screening for asbestos-related pleural disease with digital storage phosphor radiography. Invest Radiol.
$25,645-650$, (1989).

13) Schaefer CM, Green R, Oestmann JW, et al: Digital strage phosphor imaging versus conventional film radiography in CT-documented chest disease. Radiology. 174, 207-210, (1990).

14）東田善治：乳房および胸部 $X$ 線検查におけるコンピ ュテッドラジオグラフィー $(\mathrm{CR})$ の応用-乳巟微小石 灰化扔よび胸部腫瘤の検出能について一. 日放技学 誌，46,1690-1711.

15) Schaefer CM, Greene R, Hall DA, et al: Mediastinal abnormalities: detection with storage phosphor digital radiography. Radiology. 178, 169-173, (1991).

16）秋田真一：びまん性間質性肺病変における FCR ラ イフサイズ像の臨床評価。日医放会誌，51，13061313，(1991).

17) Carr JJ, Reed JC, Choplin RH, et al: Plain and computed radiography for detecting experimentally induced pneumothorax in cadavers: implications for detection in patients. Radiology. 183, 193-199, (1992).

18) Wilson AJ, Mann FA, Murphy, Jr WA et al: Photostimulable phosphor digital radiography of the extremities: diagnostic accuracy compared with conventional radiograpy. AJR. 157, 533-538, (1991).

19) Prokop M, Galanski M, Oestmann JW, et al: Storage phosphor versus screen-film radiography : effect of varing exposure parameters and unsharp masking filtering on the detectability of cortical bone defects. Radiology. 177, 109-113, (1990).

20) Langen HJ, Klein HM, Wein B et al: Digital radiography versus conventional radiography for the detection of a skull fracture under varing exposus paremeters. Invest Radiol., 28, 231-234, (1993).

21）松田秀治, 阿南充洋, 上田克彦, 他：CR の実用画像 処理 (CR の画像処理検討班), 日放技学誌, (1993). 